\title{
A CPW-Fed Metamaterial Loaded Monopole Antenna for Multiband Operation
}

\author{
S.Praveena ${ }^{1}$, R. Samson Daniel ${ }^{2}$ \\ PG Scholar, Department of ECE, K.Ramakrishnan College of Engineering, Trichy, India ${ }^{1}$ \\ Assistant Professor, Department of ECE, K.Ramakrishnan College of Engineering, Trichy, India ${ }^{2}$
}

\begin{abstract}
The hexagonal shaped patch antenna loaded with hexagonal complementary split ring resonator is presented for multiband characteristics. The better impedance matching is achieved by employing the HCSRR, the metamaterial element in the main radiating patch. The proposed antenna resonate at $2.1 \mathrm{GHz}, 6.5 \mathrm{GHz}, 10 \mathrm{GHz}$ frequency bands due to the loading of metamaterial element Hexagonal Complementary Split Ring Resonator (HCSRR). The entire size of the antenna is $20 \times 21 \times 0.8 \mathrm{~mm}^{3}$. The dielectric material used for fabricating the antenna is FR- 4 having the dielectric constant of 4.4 ( $\varepsilon r$ r) respectively. The proposed antenna offers better impedance matching, multiband and good radiation pattern characteristics. Parametric study is done for various width of HCSRR slots and by split gap for scrutinizing several characteristics of the proposed antenna. The HCSRR offers negative permittivity characteristics by its pass band behavior. The designed antenna is desirable for $\mathrm{L}, \mathrm{S}$ and $\mathrm{C}$ band applications.
\end{abstract}

Keywords: Multiband, HCSRR, Negative Permittivity, Metamaterial

\section{INTRODUCTION}

In communication field, the wireless communication is the emerging and widely used technology and acquired a great area of interest. In air, the electromagnetic signals were broadcasted mainly through the allowable devices which act as transmitter and receiver. This is how the wireless communication mainly operates or the principle of wireless communication. The major advantages of this wireless communication are reliability, ease of installation and mobility. Antenna plays a vital role in wireless communication since it provides better communication. The productivity of business can be improved by the usage of Wi-Fi antennas. Antenna which operates over multiple bands of frequencies is referred as multiband antenna.

In this multiband antenna various frequency bands were coalesced in a single antenna [6].The slot in the design can be used for bandwidth improvement [6]. Metamaterials are the artificial structure which provides the negative permittivity as well as negative permeability characteristics. The antenna loaded with metamaterial can have the unique effect on the electromagnetic waves characteristics [5]. The Split Ring Resonator (SRR), the Complementary Split Ring Resonator (CSRR), Electric Field Coupled Resonator (ELC) were some of the widely used metamaterial structures utilizing for improving the antenna characteristics and performances[5].The radiation and matching characteristics of the electric and magnetic dipole antenna has been improved by utilizing metamaterial coating.

The Split Ring Resonator (SRR) offers the negative permeability characteristics by its stop band behavior as well as Complementary Split Ring Resonator (CSRR) offers negative permittivity characteristics by its pass band behavior [7]. The negative refractive index, the reverse Snell's law and the Doppler Effect has been provided by the metamaterial structures [8]. SRR offers dual band at [9]. The microstrip antenna with different patch shapes can be analyzed by using Artificial Neural network (ANN) model, the recent model used in communication system [1]. The unique frequencies from a desired signal can be selected by using the resonator. Frequency Selective Surfaces (FSS) are mainly focused for its bandwidth improvement and frequency stabilization properties [10].

The unique frequencies from a desired signal can be selected by using the resonator. The pass band behavior of the designed antenna is managed in desired ranged by using dual mode loop resonator and two stepped impedance resonator at [4]. The SRR and CSRR were widely used for fabricating the planar microwave components and for improving the antenna performances [2].Wearable antenna now attained great area of research in communication field $[3,15]$. Stacked patch utilized for bandwidth improvement, F shaped slots improve impedance matching, array technique improves gain, the reconfiguration method improves gain, impedance matching and bandwidth [11,14]. The GPS resonant frequency can be used to identify the location [13]. The multiband characteristics are widely used for ultra wide band applications [12] 
Vol. 8, Issue 5, May 2019

In this paper, the HCSRR laden antenna has been presented for $\mathrm{L}, \mathrm{S}$ and $\mathrm{C}$ band applications. This design achieved the multiband characteristics which has great significance in wireless communication. Negative permittivity characteristics have been achieved by HCSRR slot.

\section{ANTENNA DESIGN AND SIMULATEDRESULTS}

The proposed antenna is developed first by conventional hexagonal patch antenna fed through coplanar waveguide structure acts as full ground as shown in configuration (A) of Figure 1.

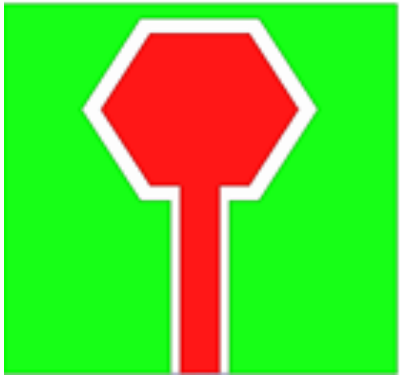

(A)

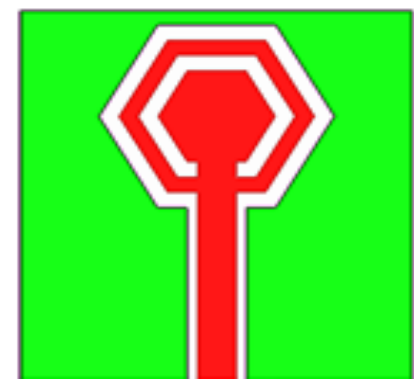

(B)

Figure 1: Design steps of proposed antenna

In the second stage, the hexagonal complementary split ring (HCSRR) is laden in the main radiating hexagonal patch as shown in configuration (B) of Figure 1. Here the HCSRR act as metamaterial element. Thus by the inclusion of HCSRR, the multiband with better impedance has been achieved. Added to this HCSRR provides negative permittivity characteristics due to its pass band behavior. Figure 2 shows the design of proposed antenna. Parameters of proposed antenna are shown in Table 1.

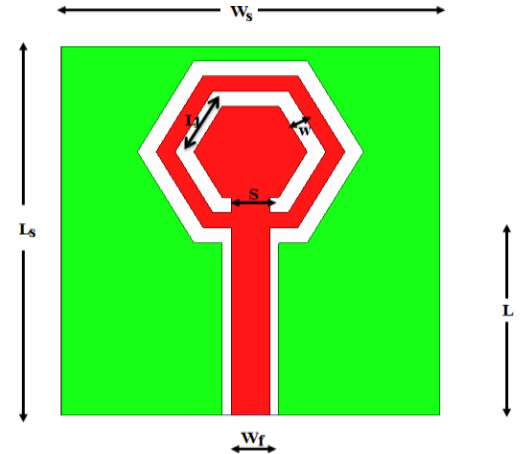

Figure 2: Design of proposed antenna

Table 1: Design parameters of antenna

\begin{tabular}{cc}
\hline Parameters & Dimension $(\mathbf{m m})$ \\
\hline LS & 21 \\
WS & 20 \\
L & 10.75 \\
Wf & 2 \\
L1 & 5 \\
S & 1 \\
w & 6 \\
\hline
\end{tabular}

The designed antenna is simulated by using the Finite element model based electromagnetic software Ansys HFSS V.15.0. foranalyzing the return loss $\mathrm{S} 11(\mathrm{~dB})$ characteristics. In structural mechanism the Finite Element model (FEM) is referred as Dominant discretization approach. Figure 3 shows the simulated $\mathrm{S} 11(\mathrm{~dB})$ characteristics of the conventional hexagonal antenna (A) and the Hexagonal complementary split ring resonator (HCSRR) laden monopole antenna (B). It shows that the conventional antenna (A) resonate at 5.5 GHz. When the metamaterial HCSRR is loaded, the proposed antenna provides tri-band resonant frequency of $2.1 \mathrm{GHz}, 6.5 \mathrm{GHz}$ and $10 \mathrm{GHz}$ suitable for $\mathrm{L}, \mathrm{S}$ and $\mathrm{C}$ band applications. Hence from the figure 3 we can infer that the HCSRR loaded monopole antenna offers better impedance matching and multiband characteristics. 


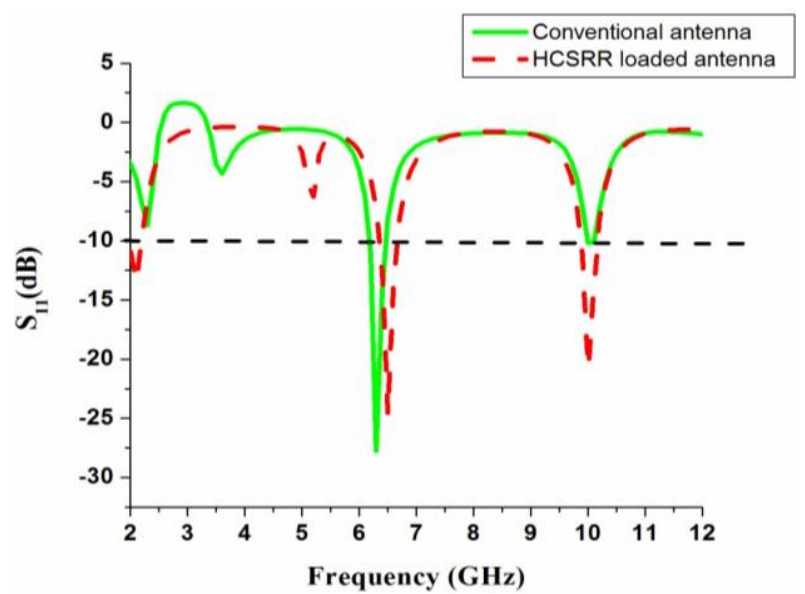

Figure 3: Simulated $\mathrm{S} 11(\mathrm{~dB})$ of conventional and proposed antenna.

\section{PARAMETRIC STUDIES}

The multiband characteristics are mainly influenced by the split gap effect in HCSRR. By increasing or decreasing the split gap there will be great variation in the return loss characteristics. There is a shift to lower resonance when the split gap decreased. The multiband will be obtained by increasing split gap respectively.

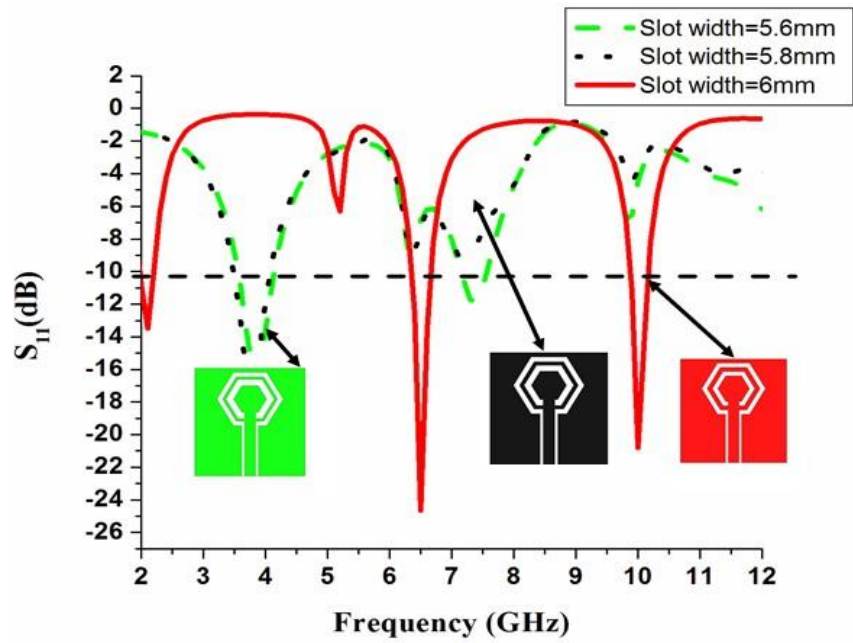

Figure 4: parametric study of slot width

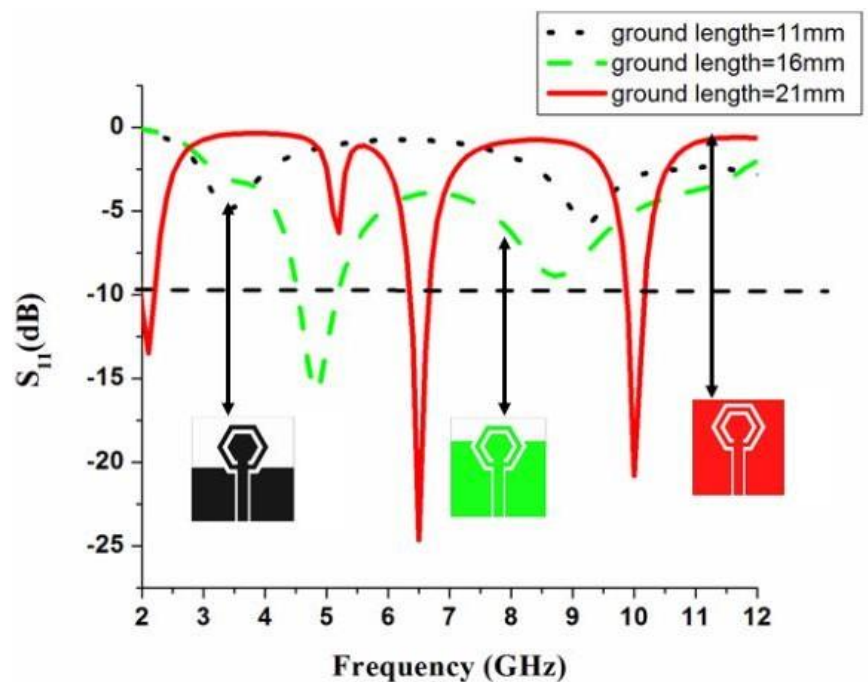

Figure 5: Parametric analysis of ground length

The parametric analysis of ground length is shown in Figure 5. In this the ground length is decreased in the order of 
Vol. 8, Issue 5, May 2019

$5 \mathrm{~mm}$ from $21 \mathrm{~mm}$ to $11 \mathrm{~mm}$. Thus in steps of $21 \mathrm{~mm}, 16 \mathrm{~mm}$ and $11 \mathrm{~mm}$. From these steps we can infer that the optimum result achieved at $21 \mathrm{~mm}$.

\section{RESULTS AND DISCUSSION}

From figure 3 it is inferred that the designed antenna offers better impedance matching with multiband characteristics. Hence the antenna is highly efficient. The resonant frequencies with corresponding return loss of the proposed antenna are $2.1 \mathrm{GHz}$ at $-13.48 \mathrm{~dB}, 6.5 \mathrm{GHz}$ at $-24.68 \mathrm{~dB}$ an $10 \mathrm{GHz}$ at $-20.80 \mathrm{~dB}$ respectively desirable for L,S and C band applications.

The designed antenna offers an simulated $-10 \mathrm{~dB}$ impedance bandwidth of $222.6 \mathrm{MHz}(1.9774 \mathrm{GHz}$ to $2.2000 \mathrm{GHz})$ at $2.1 \mathrm{GHz}, 315.7 \mathrm{MHz}(6.3502 \mathrm{GHz}$ to $6.6659 \mathrm{GHz})$ at $6.5 \mathrm{GHz}$ and $296 \mathrm{MHz}(9.8727 \mathrm{GHz}$ to $10.1687 \mathrm{GHz})$ at $10 \mathrm{GHz}$ respectively.

The radiation pattern (E-plane and $\mathrm{H}$-plane) for the all resonant frequencies such as $2.1 \mathrm{GHz}, 6.5 \mathrm{GHz}$ and $10 \mathrm{GHz}$ are shown in Figure 6 (a), 6 (b) and 6 (c) respectively. For all the resonant frequencies, it is inferred that the E-Plane is at bi-directional pattern and $\mathrm{H}$-Plane at omnidirectional pattern.

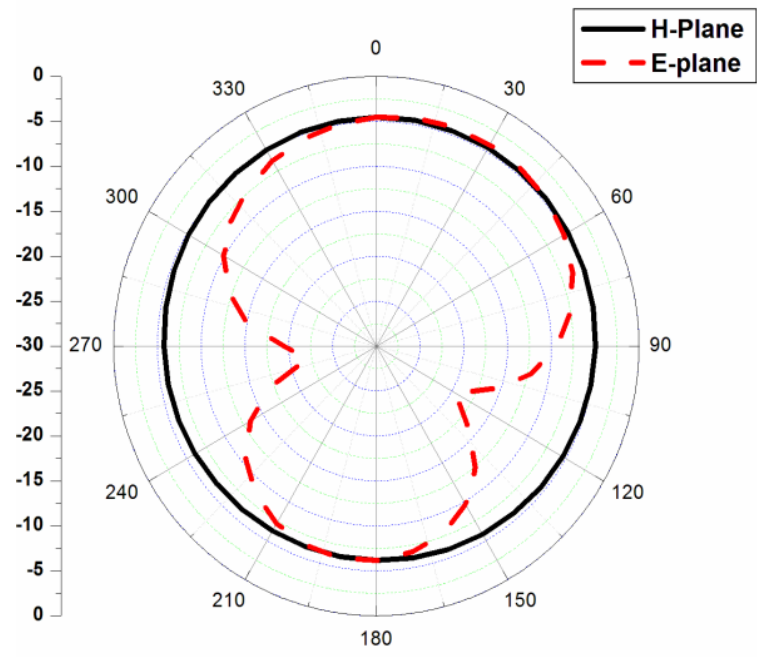

(A)

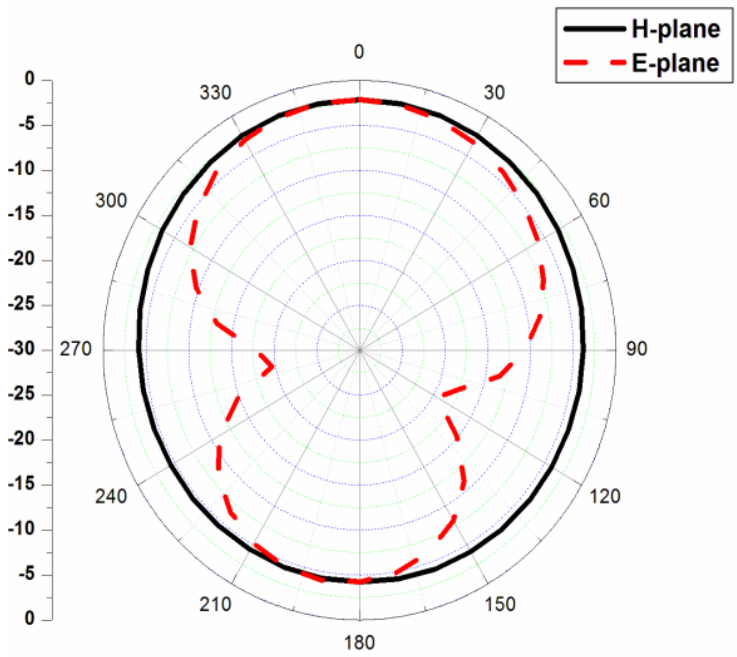

(B)

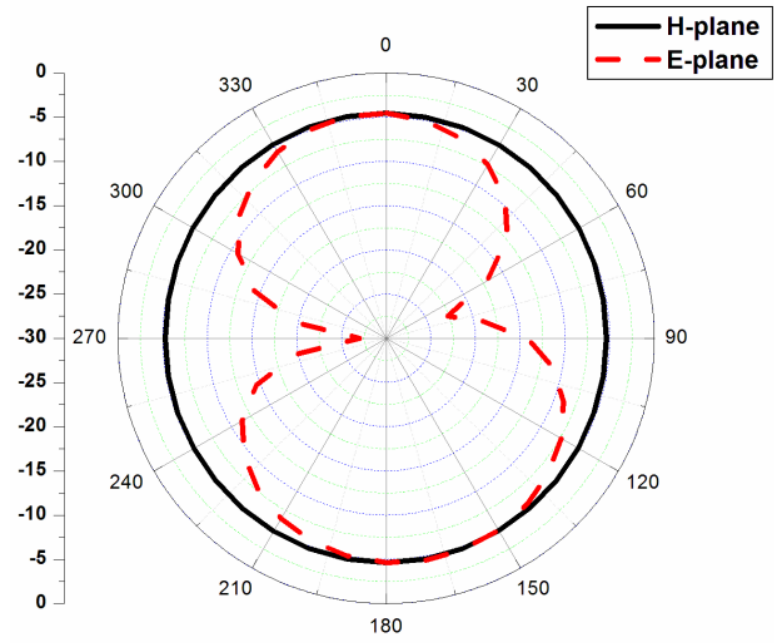

(c)

Figure 6: Far Field Radiation Pattern

The simulated VSWR of the designed antenna is shown in Figure 7. Thus the antenna offers VSWR in the range between 1 to $2 \mathrm{ie}, \mathrm{VSWR} \leq 2$. Thus the antenna is efficient. 


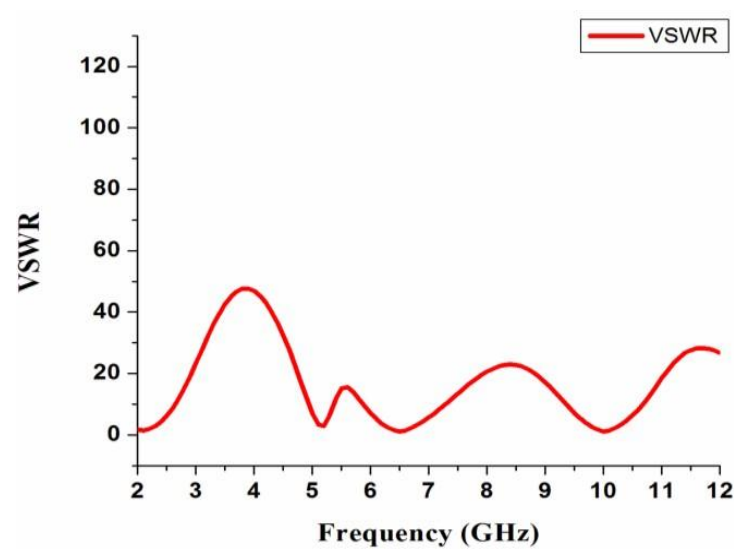

Figure 7: VSWR plot of the proposed antenna

Surface current distribution of the designed antenna is analyzed for learning and formalize the resonant frequencies as shown in Figure 8 (a)-(b)-(c).

The resonant frequency of $2.1 \mathrm{GHz}, 6.5 \mathrm{GHz}$ and $10 \mathrm{GHz}$ due to the inclusion of HCSRR with split is desirable for ISM band, $\mathrm{S}$ and $\mathrm{C}$ band applications.
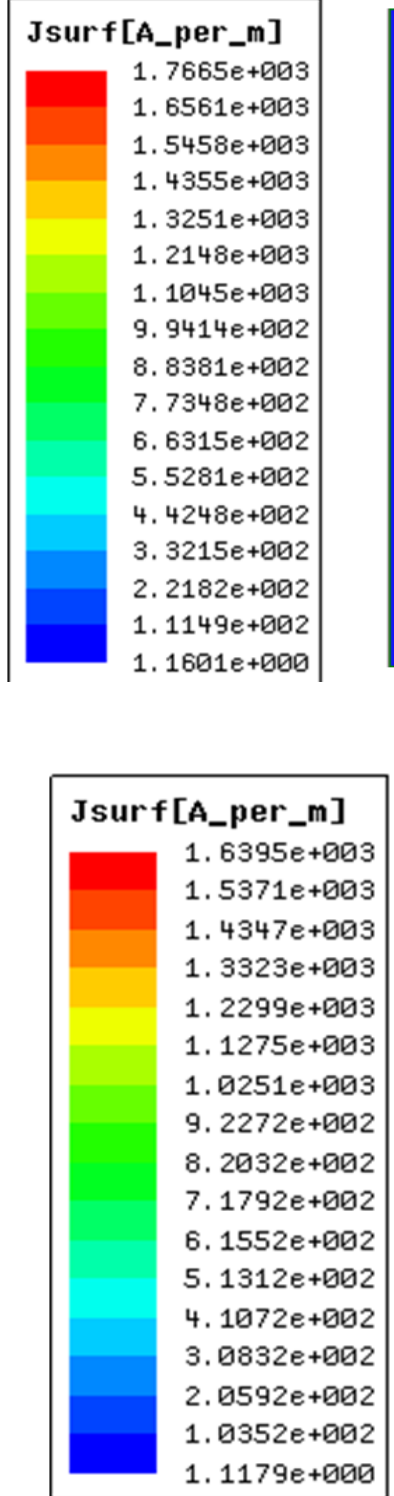

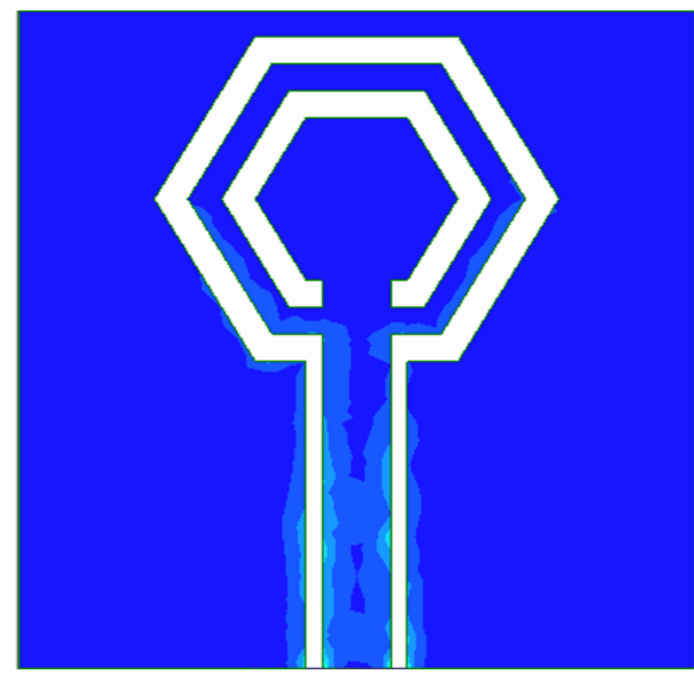

(A)

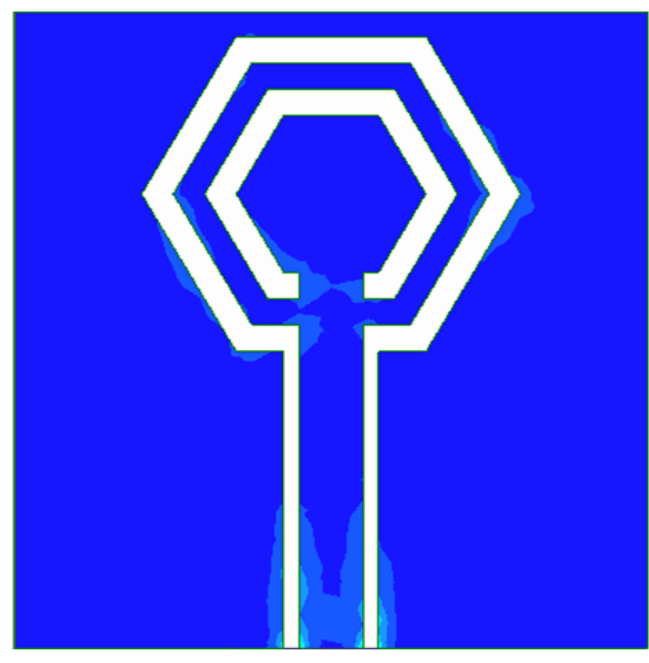

(B) 
Vol. 8, Issue 5, May 2019

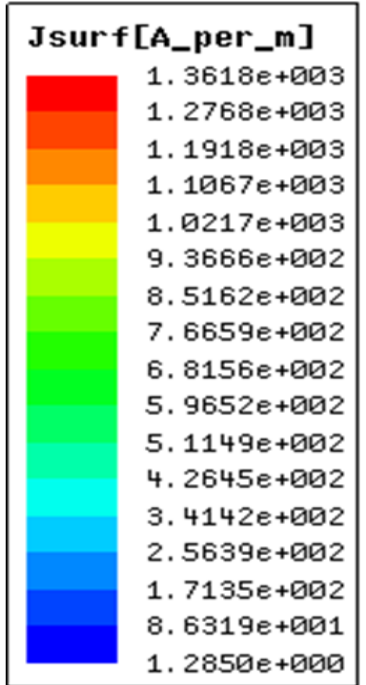

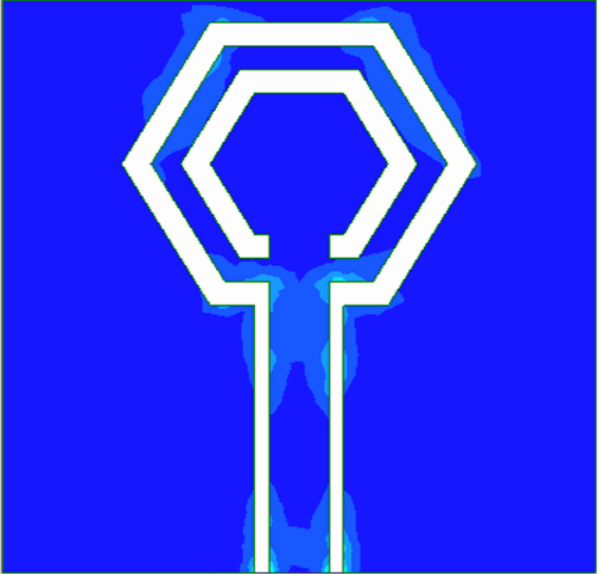

(C)

Figure 8: Surface current distribution of the designed antenna (a) $2.1 \mathrm{GHz}$ (b) $6.5 \mathrm{GHz}$ and (c) $10 \mathrm{GHz}$.

Table 2: Progression of simulated parameters

\begin{tabular}{lccc}
\hline $\begin{array}{l}\text { Proposed } \\
\text { antenna }\end{array}$ & $\begin{array}{l}\text { Resonant } \\
\text { frequency }(\mathbf{G H z})\end{array}$ & $\begin{array}{c}\text { Return } \\
\text { loss (dB) }\end{array}$ & VSWR \\
\hline Simulated & 2.1 & -13.48 & 1.5 \\
& 6.5 & -24.66 & 1.1 \\
& 10 & -20.80 & 1.2 \\
\hline
\end{tabular}

\section{CONCLUSION}

The CPW-Fed metamaterial loaded monopole antenna for multiband operation is presented. The total dimension of the designed antenna is $21 \times 20 \times 0.8 \mathrm{~mm}^{3}$. The inclusion of hexagonal complementary split ring resonator (HCSRR) is responsible for obtaining multiband characteristics. The proposed antenna is applicable for L, S and C band devices. The simulated return loss, radiation pattern and VSWR make the antenna suitable for wireless applications.

\section{REFERENCES}

[1]. Anil Kumar, B Murugeshwari, S Raghavan, Design of Substrate Integrated Waveguide Power Divider and Parameter optimization using Neural Network. IOSR Journal of Electronics and Communication Engineering (IOSR-JECE), 13(1): 37-43 (2018).

[2]. Gayathri R, and Maheswari M. Design And Fabrication Of Dual Band RFID Antenna Using Hybrid Coupler With CSRR. Pakistan Journal of Bio Technology, 14(1): 87-89 (2017).

[3]. Monisha. S, \& U.Surendar, A Survey on Wearable Antenna for ISM Band Application. IOSR Journal of Electronics \& Communications, Eng, 49-54( 2018).

[4]. Muruganantham. T, Surendar U, and Balakumar A Dual Band Bandpass Filter With Sharp Passband Resonances Using Dual-Mode SIRs. International journal of microwave applications, 6(2): 18-21 (2017).

[5]. Samson Daniel. R, Pandeeswari, and S Raghavan. Dual-band monopole antenna loaded with ELC metamaterial resonator for WiMAX and WLAN applications Applied Physics A 124 (18) :1984-1987 (2018).

[6]. Samson Daniel.RDesign and Simulation of Multiband CPW feed Ring Shaped Antenna for Wireless Applications. International Journal of Engineering Sciences \& Research Technology, 549-553 (2014).

[7]. ThamilSelvi. N, P. N. ThiruvalarSelvan, S. P. K. Babu, R. Pandeeswari, and R. Samson Daniel. A Broad-Side Coupled SRR Inspired CPW Fed Dual Band Antenna for WiMAX and Wave Applications", PIER C 80:.221 -231 (2018).

[8]. ThamilSelvi. N, P.ThiruvalarSelavan, and SPK.Babu, EC-SRR Inspired CPW-Fed Triple Band Antenna with Staircase Shaped Ground Plane for WLAN and C-band Applications, 13(4): 299 - 309, (2018).

[9]. ThamilSelvi. N, R. Pandeeswari, and P. N. ThiruvalarSelvan, An Inset-Fed Rectangular Microstrip Patch Antenna with Multiple Split Ring Resonator Loading for WLAN and RF-ID Applications, PIER C, 81:41 - 52 (2018).

[10]. VarikuntlaKrushnakanth, B.Murugeshwari,andSingaraveluRaghavan, "Design of a CPW Fed Substrate integrated waveguide using Frequency selective surface. $11^{\text {th }}$ International Radar symposium India( IRSI'17), Bangalore,India(2017).

[11]. S.Praveena, B.Murugeshwari, U.Surendar R. Kayalvizhi "A Review on Antenna Design for Millimeter Wave range", IOSR Journal of Electronics and Communication Engineering, pp. 01-06, 2018.

[12]. V.Indhumathi,B.I.S.Ronica, "Design of Koch Fractal Patch Antenna For UWB Application" Proceedings of International Conference on Engineering Trends and Science \& Humanities(ICETSH-2015).

[13]. S Shabina, Smart Helmet Using RF and WSN Technology for Underground Mines Safety, Proceedings of International Conference on 
Intelligent Computing Applications, pp.305-309,2014.

[14]. Revathi, A Jeyalakshmi, C "Robust Speech Recognition in Noisy Environment using Perceptual Features and Adaptive Filters", Proceedings of 'International Conference on Communication and Electronics Systems (ICCES 2017), IEEE explore, pp.692-696, 2018.

[15]. Revathi, A Jeyalakshmi, C 2017, 'A challenging task in recognizing the speech of the hearing impaired using normal hearing models in classical Tamil language', Journal of Engineering research, vol.5 no.2, pp.110-128, June2017.

\section{BIOGRAPHIES}

S.Praveena, is a PG Student, Department of communication systems in K.Ramakrishnan college of Engineering. She completed her BE in department of ECE at K.Ramakrishnan college of Engineering.. Her research interests in RF and Microwave Engineering.

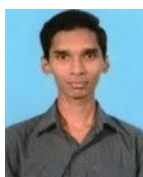

Dr. R. Samson Daniel received his B.E degree in Electronics and Communication Engineering from Shri Angalamman College of Engineering and Technology, Tiruchirappalli, M.E degree with distinction in communicationnSystems from K.Ramakrishnan College of Engineering, Tiruchirappalli. He completed his Doctoral program in the field of Metamaterial Inspired Techniques. 